\title{
Original article:
}

Ibn Tofail'sUniversity students' satisfaction evaluation towards distance learning and its impacts on the students' mental health during the Covid 19 Confinement.

Keltoum Rahali ${ }^{1}, Z a k a r i a ~ A b i d l i^{2}$,Abderrazzak Khohmimidi ${ }^{3}$, Mohamed Elhamzaoui $^{4}$, Raja Seghiri ${ }^{5}$, Khaoula Jabari ${ }^{6}$ Elmahjoub Aouane ${ }^{7}$, Abdelaziz Chaouch ${ }^{8}$

\begin{abstract}
Aims, objectives and methods: The study we have conducted aims to evaluate Moroccan students' satisfaction level with regard to the use of distance learning platforms during the Covid 19 confinement period. We also attempt to examine the impact of distance learning on the students' mental health.Our research has demonstrated that imposing distance learning as a learning process to students produces a substantial stress level within $49 \%$ of the investigated student population.Indeed, the students' full immersion in distance learning process has obviously arose technical and pedagogical brakes within (87\%) of the questioned student population, and also psychological brakes within $(27 \%)$ of the respondent population. Furthermore, the particularity of this confinement's period has brought to light three students' categories regarding the use of distance learning in their training and learning process and behavior. Recommendations:Our study's results can be considered very relevant because they show a clear correlation between the adoption of distance learning, as a new teaching approach, and, the perceived stress level $(49 \%)$ involved during this process. Therefore, the clear necessity of material, pedagogical and psychological supports to be implemented during this transition stage.

Keywords: Distance learning ; Perceived stress ; Covid 19 ; Moroccan university ; Ibn TofailUniversiy at Kénitra.
\end{abstract}

Bangladesh Journal of Medical Science, Special Issue on Covid19, 2020. Page : S 51-S 57 DOI:https://doi.org/10.3329/bjms.v19i0.48166

\section{Introduction}

With the concern of a better management of this quarantine period which the major aim is the slowdown of the Covid 19 pandemic alarming spread, Morocco has been among the first countries that implementedhealth emergency ${ }^{1}$. In this regard, the Department of National Education, Professional
Training, Higher Education and Scientific Research has swiftly made available for the students' community,as of march the 16th2020, a set of television channels, radio stations, digital portals and platforms ${ }^{2}$.This situation has immediately triggered the cancellation of the "presential" courses following the shutdown of all the schools and university

1. Keltoum Rahali, Ibn TofailUniversity-Kénitra, Faculty of Science, Laboratory: Agro Physiology, Biotechnology, Environment and Quality, Morocco.

2. Zakaria Abidli, Ibn Tofail University-Kénitra, Faculty of Science, Genetics and biometrics laboratory, Morocco.

3. Abderrazzak Khohmimidi, Researcher, Management Science, FSJES Agdal, Mohammed V University in Rabat, Morocco.

4. Mohamed Elhamzaoui, Ministry of National Education, Higher Education, Staff Training, and Scientific Research, Morocco.

5. Raja Seghiri, Laboratory of Agro-Resources, Polymers and Process Engineering, Faculty of Sciences, Ibn Tofail University, Kenitra, Morocco.

6. Khaoula Jabari, Ibn Tofail University-Kénitra, Faculty of Science, Genetics and biometrics laboratory, Morocco.

7. Elmahjoub Aouane, Ibn TofailUniversity-Kénitra, Faculty of Science, Laboratory: Agro Physiology, Biotechnology, Environment and Quality, Morocco.

8. Abdelaziz Chaouch, Ibn TofailUniversity-Kénitra, Faculty of Science, Laboratory: Agro Physiology, Biotechnology, Environment and Quality, Morocco.

Correspondence to: Zakaria Abidli, Ibn Tofail University-Kénitra, Faculty of Science, Genetics and biometrics laboratory, Morocco. Email: zakaria.abidli@uit.ac.ma 
institutions. As an aftermath of this situation, the students found themselves compelled, even though unprepared, to engage in a new learning process. We need to emphasizes the fact that the Department of National Education, Professional Training, Higher Education and Scientific Research has been very reactive to students learning needs, since the beginning of the confinement period. The Department has hence responded by making available all the necessary learning tools, and achieving the required efforts which are qualified as colossal considering the short time frame time during which the process has been implemented.Nevertheless, it seems appropriate to question ourselves about the level of acceptance, involvement and satisfaction of our students towards this new learning pattern. Indeed, due to the various quarantine measures, Moroccan university students quickly have became aware that the confinement period does not signify some kind of vacation or holiday but rather an opportunity to resume the studies and courses through a new process: remote or distance learning which has overnight kept the students away from their teachers' support.

As a matter of fact, many questions arose during the confinement's two first weeks, through social media networks regarding the quality level of distance learning and the students' perceptions of this new modus operandi and also the future of the conventional teaching and learning ${ }^{3}$.For the purpose of this research paper, our study aims to shade light on the satisfaction level of university students regarding distance learning and some of its implications.

\section{Material and research methods}

We have conducted from March 17th to April $30^{\text {th }} 2020$ a transversal study. In order to answer our research questions, we have disseminated an investigation questionnaire that is divided in three sections: the first is related to the respondents' socio demographic characteristics, the second unit of the questionnaire is composed of the PSS10 scale in order to assess the students' perceived stress level during the confinement period. The PSS10 includes two factors: The first factor contains (06) six negative items measuring the individual's"stress perception". In the opposite, the second factor contains (04) four positive items measuring the "coping with" or the adaptation to the stress ${ }^{4}$. The total stress score is obtained through the sum of the different responses after the inversion of positive items and it varies from 0 to 40 .A higher score shows a superior level of perceived stress. The third unit of the questionnaire contains (05) five items corresponding to the students' satisfaction towards distance learning.Our statistical methodology is based upon two axis: descriptive statistics and analytical statistics. The first axis is a step allowing the description and analysis of the variables object of study namely distance learning and stress. The analytical part includes the connection verification of the different variables studied by using chi-two test. Moreover, and for a better results' accuracy, we have calculated the Cronbach's alpha for the total of items. One alpha included between 0,6 and 0,8 is acceptable for an exploratory study ${ }^{5}$.The target population of the investigation is composed of Ibn Tofail's University (City of Kénitra, Morocco) students, all levels and fields of study mixed. The questionnaire was distributed to the students through their institutional emails.

On the ethical level, all the respondent students have been adequately been informed about the research's scope and purpose, about the data confidentiality and the respect of the respondents' privacy and anonymity. All the investigations' procedures have all been conducted in accordance with Ibn Tofail's University regulations' chart.

\section{Results:}

\section{A. The sociodemographic and economic parameter of our population's sample}

In our study, 123 students agreed to answer our research questionnaire, $54 \%$ are female $(n=66)$, with a sex ratio (feminine/masculine) of 1.1 . The age average of all our sample is 21 years old.

\section{B. Questionnaire validation}

\section{Perceived stress questionnaire}

The perceived stress questionnaire allowed us to grasp the stress level experienced by the students during the confinement that has been enforced by the Moroccan authorities during two to three months. The questionnaire accuracy is tested as follows:

\section{a) Questionnaire's Internal consistency:}

In order to determine the internal coherence of our questionnaire, we have calculated the Cronbach's index for all the items. The Cronbach's alpha value of the totalof our items was 0.7 , which explains the homogeneity of the different questionnaire'sdimensions (PSS10).

\section{b) Factorial analysis}

So as to perform a factorial analysis of the questionnaire, we have taken into consideration the index value of KMO and Bartlett's sphericity test. In our research, the KMO index was $0.7>0.5$ [6-7]. Thisreveals an acceptable value to perform factorial analysis. Thus the Bartlett's testsphericity is highly significant. 
Table1 : KMO Index and Bartlett's test

\begin{tabular}{ll}
\hline & Value \\
\hline KMO Index & $\mathbf{0 . 7}$ \\
Bartlett's spherecity Test & $\mathbf{0 . 0 0 1}$ \\
\hline
\end{tabular}

In our attempt to study the factorial structure of the gathered data, we have opted for the Principal Component Analysis (PCA), this latter was achieved with a varimax rotation over all the questionnaires' items. This analysis made it possible for us to keep two factors which explain $70 \%$ of the total variance. The first factor explains the variability of the items linked to negative stress (items 1,2,3,6,9 and 10), whereas the second factor indicates the variability of items related to stress adaptation (items; 4,5,7 and 8). Based on the results, we have observed satisfactory psychometric properties of PSS10 scale.

Table 2 :Indice KMO Index and Bartlett's test

\begin{tabular}{ll}
\hline Items number & Cronbach's value \\
\hline 5 & $\mathbf{0 . 7}$
\end{tabular}

c) Questionnaire's consistency regarding the students' satisfaction towards distance learning during the Covid 19 confinement period

Regarding the psychometric properties of our questionnaire related to students's satisfaction towards distance learning during the Covid 19 quarantine, we have calculated the Cronbach's index. This one is [satisfactory] with a value superior to 0,7 $(0,83)$.

Table3: Questionnaire's answers distribution dealing with distance learning.

\begin{tabular}{|c|c|c|c|}
\hline Items & Number & Percentage & P-value \\
\hline \multicolumn{4}{|c|}{ On which platform or application do you followyour training? } \\
\hline Microsoft teams & 26 & $21 \%$ & \multirow{5}{*}{$0.05 *$} \\
\hline Classroom & 22 & $18 \%$ & \\
\hline Google hangout & 8 & $7 \%$ & \\
\hline Social network & 56 & $46 \%$ & \\
\hline Other & 11 & $9 \%$ & \\
\hline \multicolumn{4}{|c|}{ How do you describe its use? } \\
\hline Easy & 48 & $39 \%$ & \multirow{4}{*}{$0.05 *$} \\
\hline Interactive & 31 & $25 \%$ & \\
\hline Adaptated to the course & 28 & $23 \%$ & \\
\hline Pedagogical & 16 & $13 \%$ & \\
\hline \multicolumn{4}{|c|}{$\begin{array}{l}\text { Are you satisfied about distance } \\
\text { learning? }\end{array}$} \\
\hline No & 72 & $59 \%$ & \multirow{2}{*}{$0.05 *$} \\
\hline Yes & 51 & $41 \%$ & \\
\hline
\end{tabular}

* The difference is significant at level 0.05 (bilateral).

During the confinement period, distance learning has been seen as an appropriate learning process to solve the issue of the presential courses' cancellation due to the health pandemic crisis in Morocco. This experience which is perceived as a panacea in this confinement period, has started despite the efforts strived, without a real prior preparedness. Besides, if teaching through information technology aims to ensure the courses' continuum, many pedagogical, technical and psychological dysfunctions have been recorded regarding distance learning.

This particular fact has consequently involved a direct impact regarding students' learning and their physical and psychological health. In this perspective, our study has set as an objective which consists on examining the impact of presential courses' cancellation on students', so we can be able to answer the following question: What is/are the effect ( $\mathrm{s}$ ) of distance learning? This question is very crucial because it tries to measure the students' familiarization with distance learning platforms.

The obtained results point out that $46 \%$ of our sample use social networks (i.e. WhatsApp) for pedagogical purposes at the expense of distance learning platforms like (Google Classroom). This explains our hypothesis that stipulates that both students and teachers are not completely familiarized with exclusive learning platforms. In other words, if the doxa defends the idea that we are dealing with a hyper "connected" generation, the opposite is quite possible this generation is not enough digitalized to easily shift towards distance learning.

As supporting evidence, $59 \%$ of the investigated population, shows a neat preference for the paper as learning medium which can be preserved for a long time unlike digital material. If the over use of paper is criticized by the ecologist community, our sample unveils a preference for this kind of physical support in terms of security and a symbol of equality to other individuals. Furthermore, during a presential course, an affective complicity between the teacher and his students is created allowing them to animate their exchanges and to weave a genuine relationship that is not possible for digital application to secure for students.

Through his presence, the teacher undertakes a double role, he is a facilitator and a mediator which are greatly needed by students. This is to announce that technology-based learning is perceived unable of efficiency compared to presential teaching because solely $13 \%$ of our sample considers pedagogical distance learning in opposition to $87 \%$ that judge it unsatisfactory at the pedagogical scale. 
Consequently, some kind of reassessment should be done regarding the learning logistic and the pedagogical practices should be adjusted in order to guarantee distance learning efficiency.

Our sample considers that remote learning is full of imperfections and several obstacles make it inappropriate at the pedagogical level and provokes a straight impact on the students' psychology. The figure below illustrates the different impediments encountered by the respondent students during distance learning activities in a confinement period:

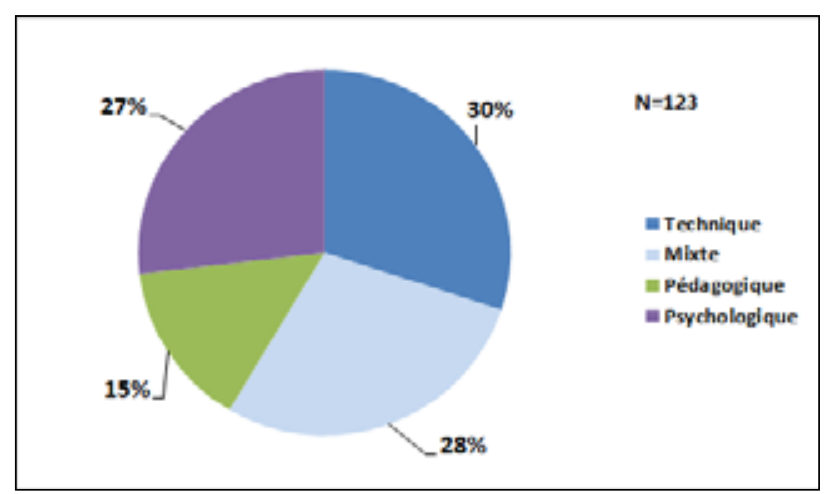

Figure 1: Distribution of main obstacles encountered by Ibn Tofail's university students during technology-based learning activities

According to the above mentioned figure we observe that many obstacles make distance learning uneasy for students. These obstacles range from multiple natures: technical, psychological or pedagogical.

a. Technical obstacles : They represent a serious issue for approximatively $30 \%$ of the questioned students, meaning 37 persons from 123 individuals population. These technical obstacles are indeed connected with the misconceptions about the use of distance learning platforms or furthermore the lack of technical assistance or again the inexistence of internet network home subscription.

b. Psychological obstacles : They reveal the dread expressed by $27 \%$ of students and concerning their hesitation and uncertainty to adapt themselves each time with a new tool or their fear about their privacy, identity confidentiality when they use distance learning process (a hacking risk for instance).

c. Various obstacles: they unveil the lack of confidence of $28 \%$ of the questioned respondents towards the trustworthiness of the Web to protect them against recurring fraudulent activities.

d. Pedagogical impediments :This category of obstacles was only mentioned by $15 \%$ of the questioned students. This leads us to deduce that during the quarantine period, the psychological issue represents a real burden for students, followed in the last rank by the pedagogical concern. Hence, the necessity to monitor and verify the anxiety level of the students' population during this specific quarantine period.

Table 4 : Distribution of the response in relation with distance learning

\begin{tabular}{lcc}
\hline \multicolumn{1}{c}{ Items } & Yes & No \\
\hline $\begin{array}{l}\text { Did distance learning modify } \\
\text { your learning ability? }\end{array}$ & $64(52 \%)$ & $59(48 \%)$ \\
Will distance learning involve an & & \\
$\begin{array}{l}\text { improvement in the future at the } \\
\text { teaching level ? }\end{array}$ & $73(59 \%)$ & $50(41 \%)$ \\
After this experience would you & & \\
like to do without presential & $70(57 \%)$ & $53(43 \%)$ \\
teacher for ever?
\end{tabular}

With the purpose to deepen our investigation, we have questioned the students if distance learning process will modify their learning ability and the value of $52 \%$ of the respondents revealed a negative direct impact which demonstrate their fear and anguish towards distance learning way.

However, $59 \%$ of the questioned students declare themselves confident in the remote learning ability to improve the teaching quality in the future. Besides, these students believe that distance learning can be a suitable means in order to fill the gaps of the current system. Besides, $57 \%$ of students declare their preference for distance learning after this experience. This lead us to conclude that it is not that the tool that seems to be problematical to students but rather the way of its implementation and the period of its application.

Indeed, this student's generation qualifies itself as technology open and savvy, easily using digital technologies and applications. Nevertheless, the problem is embodied in the manner of launching distance learning as a new learning process with no prior preparation or training that triggered student's anxiety particularly in the confinement circumstance. At the psychological level, we have observed that $49 \%$ of the questioned students declare a perceived stress (pathological).

According to the bi-varied analysis, we have observed a significant link between the students' mental health represented by their perceived stress and the satisfaction towards distance learning (chitwo=10.01; P-Value=0.01). Likewise, we have remarked that students who have experimented a perceived stress represent 3 times more than 


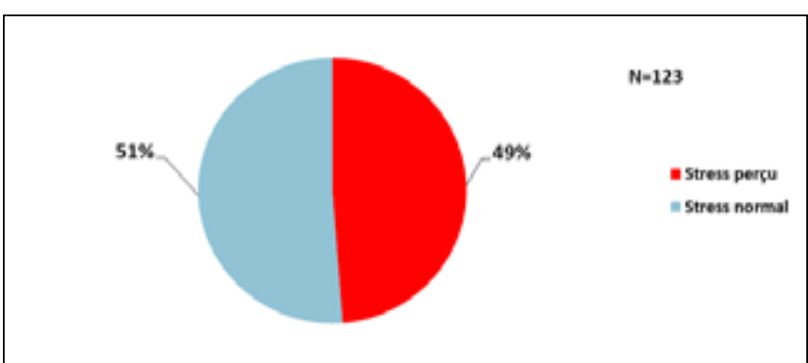

Figure 2: Repartition of Ibn Tofail'sunisersity (Kénitra) students stress level between the psychological state and the students' satisfaction towards distance learning. So as to determine this relationship we have used the (PSS10) test. The Cronbach's alpha coefficient for the PSS10 in this research was 0,83 which indicates a good internal coherence. This result is compliant to previous studies who have reported a higher internal coherence for the PSS-10 $0^{9-10-11-12-13}$ Furthermore, the corrected correlations between the elements and the total were equally situated in an acceptable range. We

Table 5:Link between satisfaction towards distance learning and mental health of Ibn Tofail's university students (Kénitra).

\begin{tabular}{|c|c|c|c|c|c|c|}
\hline \multirow[b]{2}{*}{ Inbdependent variable } & \multicolumn{2}{|c|}{ Dependent variable } & \multirow[b]{2}{*}{ Odds-Ratio } & \multirow[b]{2}{*}{ 95ICà\% } & \multirow[b]{2}{*}{ Chi-two } & \multirow[b]{2}{*}{ P-value } \\
\hline & $\begin{array}{l}\text { Not satisfied with } \\
\text { distance learning }\end{array}$ & $\begin{array}{l}\text { Satisfait with } \\
\text { distance learning }\end{array}$ & & & & \\
\hline Perceived stress & 37 & 23 & \multirow{2}{*}{3.54} & \multirow{2}{*}[1.6-7.8]{} & \multirow{2}{*}{10.01} & \multirow{2}{*}{$0.001 * *$} \\
\hline Normal stress & 35 & 28 & & & & \\
\hline
\end{tabular}

***: The La liaison is highly significant between the two variables $\mathrm{P}$-value $<0.001$

those who haven't been impacted by distance learning (odds $=3.54 ; 95 \mathrm{IC}$ to $\%=[1.6-7.8]$; chitwo $=10.01 ; \mathrm{P}-$ Value $=0.01)$.

\section{Discussion}

The main goal of our research paper study is the evaluation of university students' level of satisfaction towards the distance learning process during the confinement which was is the aftermath of the Covid 19 pandemic crisis. We have sought to respond to the following central question: Is there a significant psychological stress impact regarding the perceived satisfaction from distance learning?

As a matter of fact, the investigation's results show that in this current confinement period, the distance learning experience has witnessed the emergence of many technical, psychological and/or pedagogical obstacles. This confirmed by the satisfaction level of $41 \%$ which is very significant enough to highlight the following reasons: material reasons which are explained by the absence of a total coverage of Internet network in the kingdom of Morocco. Alongside, some vulnerable families don't own some basic media like television or the radio.The psychological motivations involve the appearance of a weak students' adhesion to distance learning as a new concept for learning and teaching. Indeed, distance learning should not limit itself to "putting online" courses materials but rather to constitute an innovative tool in the way where it should keep the ever existing relationship between the teacher, the student, the medium and the medium's content ${ }^{8}$.

In our study we have remarked a significant link need to stress the fact that the students experienced a psychological unrest during the Covid 19 quarantine period. This was revealed by our research as we have observed a very significant students' perceived stress. This particular situation could be derived from several factors, some studies conducted during the same confinement time period, unveiled that the exposition to social media was positively correlated to negative emotions such as depression and anxiety ${ }^{14-15}$. Some studies highlighted the fact that early prevention and control of Covid 19 provide some protection against psychological distress and were associated to low levels of anxiety.During the severe acute respiratory syndrome (SARS) epidemic in 2003, early prevention and control were associated with moderate anxiety levels ${ }^{16}$.

We can deduce that provided they benefit from an appropriate sanitary education, people become aware that efficient prevention and monitoring measures can protect them from infection, hence decreasing the concerns related to life and health threats. Another study has revealed that health education, particularly targeting knowledge improvement about Covid 19 among very educated individuals, can help them sustain an optimistic attitude and promote the deployment of appropriate prevention and control measures ${ }^{17-18}$. The student's psychological condition plays a paramount role in their learning process. For this purpose, the use of psychological support is indeed compulsory for students in order to ensure that they obtain good results in their learning endeavors. Ultimately, regarding pedagogical reasons, they highlight the concepts incompatibility with the 
specific pattern of some courses featuring a practical aspect and consequently identifying the teacher as the vertebral column in the training action ${ }^{19}$. This fact led some students to prefer the paper medium at the expense of digital one.In Morocco, distance learning is not a new topic. Indeed, we have already witnessed by the past, a succession of numerous distance learning programs and projects in partnership with international organisms aiming to train teachers to use different digital resources either in hard skills or soft skills.However, the particularity of distance learning action was its matching with the confinement(s) requirements, which allows us to distinguish three students' categories: those who strive themselves to follow distance courses with all the emerging stress and the equipment needed. A second category include the students who drop out distance courses during the confinement period because they lack a clear vision about their future and becoming and a which increases their stress level as a consequence. Finally, the third category of students are those wishing to benefit from this learning process, however they cannot due to the unavailability of relevant equipment at home and this fact creates for them a lasting disability and anxiety feeling

No one can neglect the fact that throughout the training action, there is a close bond that is created between the teacher, the student and the support which has not been located by students during distance learning.Hence, we observe the significant relationship between the course medium, the method and the course instructor. We, therefore, deduce consider that distance learning is an alternative solution to override the issue of coming to class rooms amidst this confinement period.

Nevertheless, the pedagogical action has not been completely examined which leads us to suggest that in the future, it would be appropriate to switch between the two concepts: conventional and mediatized along with a good training effort for those who will use this last kind in order to be skillful in its utilization ${ }^{20}$ and bypass the different psychological and pedagogical brakes.

\section{Conclusion :}

The use of distance learning platforms is not new within Moroccan university. However, its enforcement during a special confinement circumstance due to Covid 19 pandemic crisis, made it specific and compulsory for all the students, a statement that has motivated our investigation and its contextualization in the university setting namely, Ibn Tofail's university at kénitra city, Morocco.

This research has been conducted in a particular confinement context. Given these circumstance, we had no trouble in gathering all the necessary required data through email, in order to state that there is clearly a direct relationship between the level of student satisfaction towards distance learning andits impact on mental health and perceived stress.

Obviously, our research is merely a trigger to motivate other researchers to further dig the field in this perspective in order to implement real mechanisms (pedagogical cell and psychological support) able to enhance our universities' actions regarding the achievement of their goals in distance learning.

\section{The added value of the study :}

This scientific contribution encourage all persons in charge of the pedagogical system to further involvement in psychological, material and pedagogical matters in order to ensure the success in the future of distance learning. The added value of our study is to demonstrate the situation of the psychological state of the students and their satisfaction with distance learning during the period of Covid 19 in Morocco.

\section{Source of funding :}

This study is not funded

\section{Conflict of Interest :}

No conflict of interest

\section{Ethical clarity:}

Our study respects the ethical aspects declared by the University Ibn Tofail of Kenitra, so we kept the anonymity of the participants.

\section{Contribution of the authors}

All authors contributed to this work and read and approved the final version of the manuscript. 
Bangladesh Journal of Medical Science, Vol : 19 Special Issue on Covid19, 2020

\section{References:}

1. Otmani A, Benchrif A, Tahri M, BounakhlabM,ElMahjoubC, El BouchcM ,Krombid M.Impact of Covid-19 lockdown on PM10, SO2 and NO2 concentrations in Salé City(Morocco).Science of The Total Environment.2020;735(15) : 139541.

2. Ministère de l'Education Nationale, de la Formation professionnelle, de l'Enseignement Supérieur et de la Recherche Scientifique. Covid-19: Bilan du Ministère de l'Education Nationale, de la Formation professionnelle, de l'Enseignement Supérieur et de la Recherche Scientifique.2020.Consulted(26/05 /2020).Available :https://www.men.gov.ma/Fr/Pages/Bilan.aspx

3. Daniel F, Cédric D. Principes pratiques de l'animatique des groupes. Stratégies d'animation en vue d'un apprentissage expérientiel.Consulted (13/06/2020). Available :https://www.cairn.info/revue-les-cahiersinternationaux-de-psychologie-sociale-2015-4page-683.htm?contenu=article.

4. Ben Loubir D, Serhier Z, Otmani N, Housbane S, Ait Mouddene N, Agoub M, Bennani Othmani M.Le stress perçu: validation de la traduction d'une échelle de mesure de stress en dialecte marocain. Pan Afr Med J. 2015; 21: 280.

5. DMSP Research Centre. Proposition of a contextualizedscale of measurementteam learning: An ExploratoryAnalysis. Université de Paris-Dauphine, Paris,France. 2003.Consulted(26/05/2020).Available : https://basepub.dauphine.fr/bitstream/ handle/123456789/4299/CR321. pdf\%3Bsequence\%3D1

6. Johnson RA, Wichern DW. AppliedMultivariateCorresp ondenceAnalysis.6thedition.Prentice-Hall, editors.USA: UpperSaddle River, NJ. 2007.

7. Yves E, Pras B, Roux E. Market-Etudes et recherches en marketing. $2^{\text {nd }}$ ed.Dunod, editors. France: Gestion Sup. 2003.

8. Kaddouri, M, Bouamri, A. Usage de plateformes d'enseignement à distance dans l'enseignement supérieur marocain : avantages pédagogiques et difficultés d'appropriation.Consulted(26/05/2020).

Available : https://journals.openedition.org/ questionsvives/93

9. AlDubai SAR, Alshagga MA, Rampal KG, Sulaiman NA. Factor Structure and Reliability of the Malay Version of the Perceived Stress Scale among Malaysian Medical Students. Malays J Med Sci MJMS. juill 2012;19(3): 43-9
10. Maroufizadeh, S, Zareiyan A, Sigari N. Reliability and validity of Persian version of perceived stress scale (PSS10) in adults with asthma. Arch. Iran. Med.2014;17: 361-365

11. Amini P, Maroufizadeh, S, Omani Samani, R. Factor structure of the hospitalanxiety and depressionscale (HADS) in Iranian infertile patient. Int. J. Reprod. Biomed.2017;15: 287-296

12. LeungD.Y, LamT.-H,. Chan S.S.Three versions of perceived stress scale: validation in a sample of Chinesecardiac patients whosmoke BMC Public Health. 2010;10- 513

13. RobertiJ.W, HarringtonL.N.,StorchE.A.Furtherpsycho metric support for the 10-item version of the perceived stress scale $J$. College Counseling.2006;9:135-147

14. WangZ., ChenJ.,.BoydJ.E, ZhangH.,JiaX., QiuJ., Xiao Z. Psychometricproperties of the Chinese version of the perceived stress scale in policewomenPloS One.2011;6 e28610

15. GaoJ,.ZhengP, JiaY., al. Mental healthproblems and social media exposureduring COVID-19 outbreakPLoS One.2020;15(4) e0231924

16. JinghuiC, YuxinY, Dong W. Mental healthstatus and itsinfluencingfactorsamongcollegestudentsduring the epidemic of COVID-19 J. South. Med. Univ.2020; 40(2):171-176

17. Zhang $\mathrm{D}$, Zhu N, Wang W, et al. A novel corona virus from patients withpneumonia in China, 2019. N Engl J Med. 2020;382:727-733.

18. Chan JF, Yuan S, Kok KH, et al. A familial cluster of pneumoniaassociatedwith the 2019 novel corona virus indicatingperson-to-person transmission: a study of a family cluster. Lancet 2020;395:514-523.

19. De Lièvre, DepoverC, QuintinJJ, DecampsS, Les représentations a priori et a posteriori qu'ont les apprenants du rôle du tuteur dans une formation à distance, 2003 - edutice.Consulted(26/05 /2020). Available :https://edutice.archives-ouvertes.fr/ edutice-00000131

20. Jacquinot, G, ChoplinH. La démarche dispositive aux risques de l'innovation.Consulted(26/05/2020). Available : http://www.education-permanente.fr/ public/articles/articles.php?id revue $=152 \&$ id $\underline{\operatorname{article}=221}$ 